\title{
Hypermethylation of the $p 16$ Gene and Lack of p16 Expression in Hepatoblastoma
}

\author{
Yhong-Hee Shim, Ph.D., Hye-Jung Park, B.S., Mi Sun Choi, M.D., Jung Sun Kim, M.D., \\ Hanseoung Kim, M.D., Jong Jae Kim, M.D., Ja-June Jang, M.D., Eunsil Yu, M.D. \\ Department of Pathology, Asan Medical Center, University of Ulsan College of Medicine (Y-HS, YMK, \\ MSC, JSK, EY); and Department of Pathology, Seoul National University College of Medicine (HK, JJK, \\ $J-J J)$, Seoul, Korea
}

Hepatoblastoma is the most frequent pediatric liver tumor that develops mostly in young children. Abnormal regulation of cell cycle regulatory genes including $p 16$ has been described, displaying no p16 mRNA and p16 protein in hepatoblastomas. The inactivation of $p 16$, leading to the disruption of cell cycle control is involved in many types of human malignancies. However, the mechanism of the $p 16$ inactivation in hepatoblastomas has not yet been elucidated. In this present study, we examined the methylation status of the $p 16$ gene promoter by using methylation-specific PCR in 24 cases of hepatoblastomas and in 20 cases of corresponding nonneoplastic liver tissue. Aberrant methylation of 5' CpG islands of p16 was present in 12 of 24 (50.0\%) cases of hepatoblastoma. Clinicopathologic parameters were not associated with the methylation status of p16. To correlate the methylation status of p16 with the expression of p16, immunohistochemical staining was done in tumors and nonneoplastic liver tissue. All non-neoplastic liver tissues displayed moderate, but heterogeneous immunoreactivity for p16. Eight of 12 (66.6\%) methylation-positive hepatoblastomas showed a complete lack of immunoreactivity for p16. The other 4 methylation-positive hepatoblastomas had heterogeneous immunoreactivity. Nine of 12 (75.0\%) unmethylated cases of hepatoblastoma displayed diffuse immunoreactivity, whereas 3 cases of unmethylated hepatoblastoma were not immuno-

\footnotetext{
Copyright (C) 2003 by The United States and Canadian Academy of Pathology, Inc.

VOL. 16, NO. 5, P. 430, 2003 Printed in the U.S.A.

Date of acceptance: February 24, 2003.

This study was supported by Grant 2001-270 (YHS) from the Asan Institute for Life Sciences, Seoul, Korea and the grant 21C Frontier Functional Genome Project (FG-1-4-02) from the Ministry of Science and Technology of Korea.

Address reprint requests to: Eunsil Yu, M.D., Ph.D., Department of Pathology, University of Ulsan College of Medicine Asan Medical Center, 388-1 Pungnap-dong, Songpa-gu, Seoul 138-736, Korea; fax: +82-2-4727898; e-mail: esyu@amc.seoul.kr.

DOI: $10.1097 / 01 . M P .0000066799 .99032 . A 7$
}

stained for p16. Our data indicate that the hypermethylation of p16 is a major mechanism of the transcriptional repression of p16 in hepatoblastomas, and we suggest that the inactivation of $p 16$, leading to the lack of p16, may play an important role in the tumorigenesis of hepatoblastomas.

KEY WORDS: Hepatoblastoma, Immunohistochemistry, Methylation, p16, PCR.

Mod Pathol 2003;16(5):430-436

Hepatoblastoma is the most frequent pediatric liver tumor that develops mostly in young children $<2$ years of age (1). The histopathologic characteristics of hepatoblastoma are well known, and hepatoblastoma prognosis has improved significantly as a result of the application of preoperative chemotherapy and has a current projected 3-year overall survival rate of $62-70 \%$ (2). Regarding the pathogenesis of hepatoblastoma, several molecular mechanisms have been suggested, including loss of heterozygosity on chromosome 11p (3) and alterations of the APC (4) or p53 (5) genes. In addition, transcriptional alterations of cell cycle regulatory genes have been reported recently $(6-8)$.

Abnormal control of the cell cycle, especially in the transition from the G1 to the S phase, is involved in many types of human carcinogenesis (9). Among the elements of the complex molecular machinery of the G1-phase progression, p16 is a negative regulatory protein, whereas cyclin D1 and cyclin-dependent kinase $4(\mathrm{Cdk} 4)$ are positive regulators. P16 binds competitively to the Cdk 4, which inhibits the interaction of Cdk 4 with cyclin D1 and leads to the inhibition of the G1 phase of the cell cycle $(10-12)$. Thus, the inactivation of the $p 16$ gene, leading to the disruption of cell cycle control, is involved in the pathogenesis of many types of human malignant tumors (13-15). An analysis of cell cycle regulators in hepatoblastomas (6) including the $p 16$ gene did not detect deletions or point mutations of the $p 16$ gene, although the $p 16$ gene 
was not transcribed in the tumor tissues as well as it was transcribed in the matched normal liver tissue. In addition, an immunoblot analysis demonstrated that the level of the $p 16$ transcripts correlated well with the p16 protein level (6). However, the investigators did not elucidate the mechanism of the $p 16$ gene inactivation. In contrast, Kim et al. (7) reported that p16 protein was expressed in all areas of a tumor in 6 of 17 sporadic hepatoblastomas, whereas the expression of p16 was inconclusive in the remaining 11 cases. These contrasting observations suggest that there may be a subpopulation of hepatoblastomas in which p16 expression is negatively regulated. Therefore, in our present study, we examined the expression of the p16 protein and the methylation status of the pl6 gene promoter to characterize the mechanism of the $p 16$ inactivation and role of p16 protein in the development of hepatoblastomas.

\section{MATERIALS AND METHODS}

\section{Tissue Samples}

We retrieved 24 cases of hepatoblastoma from the files of the departments of pathology of Asan Medical Center and Seoul National University Hospital between 1991 and 2000. Most patients did not receive preoperative chemotherapy or radiotherapy. All patients underwent tumor resection of curative intent. Representative sections from the tumor and non-neoplastic liver were fixed in $10 \%$ buffered formalin and embedded in paraffin.

\section{DNA Extraction and Methylation-Specific PCR (MSP)}

Tissues were digested in a lysis buffer $(50 \mathrm{~mm}$ Tris, pH 8.5; 1 mm EDTA; 0.5\% Tween 20) with proteinase $\mathrm{K}(500 \mu \mathrm{g} / \mathrm{mL}$, Boehringer Mannheim, Germany) at $60^{\circ} \mathrm{C}$ for 2 days, and after boiling for 2 minutes, the sample was centrifuged at 13,000 rpm. The supernatant was directly modified with sodium bisulfite to determine the methylation status of the p16 gene by MSP, as described elsewhere (16). PCR was performed at $94^{\circ} \mathrm{C}$ for 5 minutes, followed by 28 cycles at $94^{\circ} \mathrm{C}$ for 30 seconds, $65^{\circ} \mathrm{C}$ for 30 seconds, and $72^{\circ} \mathrm{C}$ for 30 seconds, with a final extension for 10 minutes at $72^{\circ} \mathrm{C}$. The reaction mixture was in a $25-\mu \mathrm{L}$ volume containing $50 \mathrm{ng}$ of modified DNA, 10 pmol of primers, $0.2 \mathrm{~mm}$ of dNTP, and $1 \mathrm{U}$ of Taq polymerase (Takara, Kyoto, Japan) in a $1 \times$ PCR buffer (10 mm Tris, pH 8.3; $50 \mathrm{~mm} \mathrm{KCl}$; and $1.5 \mathrm{~mm} \mathrm{MgCl}_{2}$ ). Sequences of PCR primers were the same as described elsewhere (16). The PCR products were analyzed on a $2.5 \%$ agarose gel, stained with ethidium bromide, and visualized by UV illumination.

\section{DNA Sequencing}

The PCR products were purified using a JETSORB gel extraction kit (Genomed, Bad Oeynhausen, Germany), and both strands were sequenced with both PCR primers by an ABI PRISM $377 \times$ L DNA sequencer (PE Biosystem) for confirmation.

Immunohistochemistry and Analysis of Immunohistochemical Results

Four- to $6-\mu \mathrm{m}$-thick sections were cut from the $10 \%$ buffered formalin-fixed and paraffinembedded tissues. The sections were mounted on poly-L-lysine-coated glass slides and baked at $60^{\circ} \mathrm{C}$ for 15 minutes. The slides were deparaffinized in xylene, rehydrated in graded alcohol, and washed in tap water. Endogeneous peroxidase activity was blocked by incubating sections with $3 \% \mathrm{H}_{2} \mathrm{O}_{2}$. The slides were placed in a steam cooker filled with a 10 mM sodium citrate buffer, $\mathrm{pH}$ 6.0, for antigen retrieval. After treatment with $10 \%$ normal goat serum for 10 minutes to block nonspecific protein binding, a 1:100 dilution of a mouse monoclonal antibody to p16 (SC1661; Santa Cruz Biochemicals, Santa Cruz, CA) was applied for 1 hour. After reaction with a mouse biotinylated secondary antibody for 1 hour, antigen-antibody reactions were visualized using a streptavidin-horseradish peroxidase conjugate (DAKO LSAB kit; DAKO, Los Angeles, CA) with diaminobenzidine as the chromogen. The slides were counterstained with Harris hematoxylin for 3-5 minutes.

Two independent pathologists screened all sections. Cytoplasmic immunoreactivity was ignored, and only nuclear staining was interpreted as positive immunoreactivity for p16. Normal lymphocytes or Kupffer cells were used as an internal positive control. We defined the immunostaining results as follows: negative, $<10 \%$ of tumor cells were positive; heterogenously positive, $10-75 \%$ of tumor cells were positive; diffusely positive, $>75 \%$ of tumor cells were positive.

\section{RESULTS}

\section{Clinicopathologic Analysis}

Clinicopathologic data on each patient, including histologic classification (17), are presented in Table 1. Staging is based on the system devised by Greenberg and Filler (18). The median age of patients was 2 years. During the follow-up period, five cases recurred, including three cases that had metastasized.

\section{Methylation Status of the $p 16$ Gene in Hepatoblastomas}

Aberrant hypermethylation of 5' $\mathrm{CpG}$ islands of the $p 16$ gene was detected in 12 of $24(50.0 \%)$ cases 
TABLE 1. Clinicopathologic Summary of 24 Hepatoblastomas

\begin{tabular}{|c|c|c|c|c|c|c|c|c|c|c|}
\hline \multirow{2}{*}{$\begin{array}{l}\text { Case } \\
\text { No. }\end{array}$} & \multirow{2}{*}{$\begin{array}{c}\text { Age } \\
\text { (months) }\end{array}$} & \multirow{2}{*}{ Sex } & \multirow{2}{*}{$\begin{array}{l}\text { Size } \\
(\mathrm{cm})\end{array}$} & \multirow{2}{*}{$\begin{array}{c}\text { Histologic } \\
\text { Classification }\end{array}$} & \multirow{2}{*}{ Stage } & \multicolumn{3}{|c|}{ Clinical Features } & \multicolumn{2}{|c|}{ p16 Methylation } \\
\hline & & & & & & Metastasis & Recurrence & Outcome & Tumor & Nontumor \\
\hline 1 & 5 & $\mathrm{~F}$ & 13 & $\mathrm{E}+\mathrm{F}$ & I & $\mathrm{N}$ & $\mathrm{N}$ & A & $\mathrm{M}$ & $\mathrm{U}$ \\
\hline 2 & 36 & M & 12 & $\mathrm{~F}$ & III & $\mathrm{N}$ & $\mathrm{N}$ & A & $\mathrm{M}$ & $\mathrm{U}$ \\
\hline 3 & 17 & $\mathrm{~F}$ & 10 & $\mathrm{~F}$ & IV & $\mathrm{Y}$ & $\mathrm{N}$ & $\mathrm{D}$ & M & $\mathrm{U}$ \\
\hline 4 & 14 & $\mathrm{M}$ & 11 & $\mathrm{~F}$ & I & $\mathrm{N}$ & $\mathrm{N}$ & A & M & $\mathrm{U}$ \\
\hline 5 & 12 & $\mathrm{M}$ & 8 & $\mathrm{E}+\mathrm{F}$ & I & $\mathrm{N}$ & $\mathrm{N}$ & A & M & $\mathrm{NC}$ \\
\hline 6 & 14 & $\mathrm{~F}$ & 4 & $\mathrm{~F}$ & I & $\mathrm{N}$ & $\mathrm{N}$ & A & M & $\mathrm{U}$ \\
\hline 7 & 9 & M & 7.5 & M & I & $\mathrm{N}$ & $\mathrm{N}$ & A & M & $\mathrm{U}$ \\
\hline 8 & 37 & M & 10.5 & $\mathrm{~F}$ & I & $\mathrm{N}$ & $\mathrm{N}$ & A & $\mathrm{M}$ & $\mathrm{U}$ \\
\hline 9 & 43 & M & 6 & $\mathrm{E}+\mathrm{F}$ & I & $\mathrm{L}$ & $\mathrm{L}$ & $\mathrm{L}$ & $\mathrm{M}$ & $\mathrm{U}$ \\
\hline 10 & 384 & $\mathrm{~F}$ & 15 & Macro & IV & $\mathrm{Y}$ & $\mathrm{N}$ & A & $\mathrm{M}$ & $\mathrm{U}$ \\
\hline 11 & 6 & $\mathrm{~F}$ & 16 & $\mathrm{E}+\mathrm{F}$ & II & $\mathrm{N}$ & $\mathrm{N}$ & $\mathrm{D}$ & M & $\mathrm{U}$ \\
\hline 12 & 4 & $\mathrm{M}$ & 8.5 & $\mathrm{E}+\mathrm{F}$ & I & $\mathrm{N}$ & $\mathrm{N}$ & A & $\mathrm{M}$ & $\mathrm{U}$ \\
\hline 13 & 40 & $\mathrm{M}$ & 8 & $\mathrm{E}+\mathrm{F}$ & IV & $\mathrm{Y}$ & $\mathrm{N}$ & A & $\mathrm{U}$ & $\mathrm{NC}$ \\
\hline 14 & 3 & $\mathrm{~F}$ & 8 & $\mathrm{~F}$ & IV & $\mathrm{Y}$ & $\mathrm{N}$ & $\mathrm{D}$ & $\mathrm{U}$ & $\mathrm{U}$ \\
\hline 15 & 11 & $\mathrm{M}$ & 15 & $\mathrm{M}$ & I & $\mathrm{N}$ & $\mathrm{N}$ & A & $\mathrm{U}$ & $\mathrm{U}$ \\
\hline 16 & 7 & $\mathrm{M}$ & 9 & $\mathrm{E}+\mathrm{F}$ & I & $\mathrm{N}$ & $\mathrm{N}$ & A & $\mathrm{U}$ & $\mathrm{NC}$ \\
\hline 17 & 24 & $\mathrm{~F}$ & 6 & $\mathrm{E}+\mathrm{F}$ & I & $\mathrm{N}$ & $\mathrm{N}$ & A & $\mathrm{U}$ & U \\
\hline 18 & 24 & $\mathrm{~F}$ & 7 & M & I & $\mathrm{N}$ & $\mathrm{N}$ & A & U & $\mathrm{U}$ \\
\hline 19 & 18 & $\mathrm{~F}$ & 8 & $\mathrm{E}+\mathrm{F}$ & IV & $\mathrm{Y}$ & $\mathrm{Y}$ & A & $\mathrm{U}$ & $\mathrm{U}$ \\
\hline 20 & 24 & $\mathrm{M}$ & 4 & M & I & $\mathrm{N}$ & $\mathrm{N}$ & A & $\mathrm{U}$ & $\mathrm{U}$ \\
\hline 21 & 17 & $\mathrm{~F}$ & 7 & M & I & $\mathrm{N}$ & $\mathrm{Y}$ & A & $\mathrm{U}$ & $\mathrm{U}$ \\
\hline 22 & 36 & M & 8 & M & I & $\mathrm{N}$ & $\mathrm{N}$ & A & $\mathrm{U}$ & $\mathrm{U}$ \\
\hline 23 & 24 & M & 4 & M & I & $\mathrm{N}$ & $\mathrm{N}$ & A & $\mathrm{U}$ & $\mathrm{NC}$ \\
\hline 24 & 1 & $\mathrm{~F}$ & 12 & $\mathrm{~F}$ & II & $\mathrm{N}$ & $\mathrm{N}$ & A & $\mathrm{U}$ & $\mathrm{U}$ \\
\hline
\end{tabular}

$\mathrm{F}=$ female; $\mathrm{M}=$ male; $\mathrm{E}=$ embryonal and fetal pattern; $\mathrm{F}=$ fetal pattern; $\mathrm{M}=$ mixed epithelial and mesenchymal type; Macro = macrotrabecular pattern; $\mathrm{N}=$ no; $\mathrm{Y}=$ yes; $\mathrm{L}=$ lost $\mathrm{A}=$ alive; $\mathrm{D}=$ dead; $\mathrm{M}=$ methylated; $\mathrm{U}=$ unmethylated; $\mathrm{NC}=$ not checked.

of hepatoblastoma by MSP (Fig. 1 and Table 2), whereas no aberrant methylation was detected in 20 cases of non-neoplastic liver. Specificity of the p16 methylation status was confirmed by bisulfite sequencing analysis (Fig. 2). Bisulfite sequencing of methylated p16 gene in three cases revealed that all $10 \mathrm{CpG}$ sites in the genes promoter remained cytosine (Fig. 2). This indicated that cytosine in the CpG site in the methylated $p 16$ gene was $100 \%$ methylated because methylated cytosine remains after bisulfite treatment, maintaining the $\mathrm{CpG}$ site. Un-
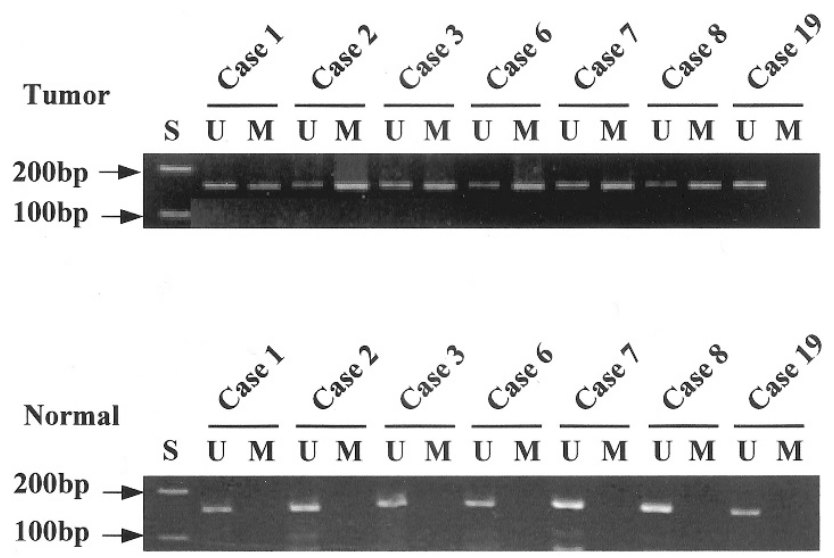

FIGURE 1. Methylation status of $p 16$ in methylated (Cases $1,2,3,6$, 7, and 8) and unmethylated (Case 19) hepatoblastomas (Tumor) and their normal livers (Normal). DNA extracted from hepatoblastomas was amplified by PCR with primers specific to the unmethylated (U) or the methylated (M) CpG islands of the $p 16$ gene after modification with sodium bisulfite. The expected sizes of the PCR products of p16 were $151 \mathrm{bp}$ with U primers and $150 \mathrm{bp}$ with M primers. Molecular size markers are in S lane.
TABLE 2. Correlation of the Expression of p16 with the Methylation Status of $p 16$ in Hepatoblastomas

\begin{tabular}{lccc}
\hline \multirow{2}{*}{ p16 Hypermethylation } & \multicolumn{2}{c}{ p16 Immunostaining } & \multirow{2}{*}{ Total } \\
\cline { 2 - 3 } & \multicolumn{2}{c}{+} & \\
\hline Positive & 4 & $8(66.6 \%)$ & 12 \\
Negative & $9(75.0 \%)$ & 3 & 12 \\
Total & 13 & 11 & 24 \\
\hline
\end{tabular}

methylated cytosine is changed to uracil after bisulfite treatment and becomes thymine during PCR amplification. Clinicopathologic parameters, including histologic type and tumor size, were not associated with the methylation status of the $p 16$ gene.

Methylation Density of CpG Islands in the p16 Gene

In 4 cases of methylation-positive hepatoblastomas, the expression of p16 was the same as that in the surrounding non-neoplastic liver tissue. The discrepancy between the methylation status of $p 16$ and the immunoreactivity for p16 could be related to the methylation density of the CpG islands because it has been shown that the level of transcriptional repression is dependent on methylation density. To clarify this discrepancy, we examined three cases of methylation-positive and p16-expressing hepatoblastoma (Cases 10, 11, and 12) and two cases of methylation positive but p16-negative hepatoblastoma (Cases 3 and 5) for the methylation density of the $p 16$ gene using bisulfite sequencing 
analysis. We sequenced the amplified PCR products of the $p 16$ gene, covering the region +167 to +317 (22). Five methylation-positive cases were extensively methylated, and $10 \mathrm{CpG}$ sites examined contained methylated cytosine (Fig. 2). This demonstrated that the p16 methylation in the $10 \mathrm{CpG}$ islands of the promoter region had no bearing on pl6 gene expression.

\section{Expression of p16 Protein in Hepatoblastomas}

To correlate the methylation status of the $p 16$ gene with the expression of p16, immunohistochemical analysis was done in the hepatoblastoma as well as in the surrounding non-neoplastic liver tissue. All non-neoplastic liver tissue displayed moderate immunoreactivity for p16 in most liver cell nuclei (Fig. 3A). Eight of 12 (66.6\%) methylation-positive cases revealed a complete lack of immunoreactivity for p16 (Fig. 3B). The other 4 methylation-positive cases had heterogeneous immunoreactivity (Fig. 3C-3D). Nine of 12 (75.0\%) unmethylated cases of hepatoblastoma displayed diffuse immunoreactivity (Fig. 3E-F), whereas 3 cases of unmethylated hepatoblastoma were negative for $\mathrm{p} 16$. The correlation between the immunohistochemical results and the methylation status was not, however, statistically significant ( $P$ $=.1$, Fisher's exact test). The expression of p16 was not associated with histologic subtypes of hepatoblastoma.

\section{DISCUSSION}

In the present study, we first report a high frequency of aberrant methylation of the $p 16$ gene promoter (50.0\%) in hepatoblastomas. p16 is a negative cell cycle regulator that is involved in the pathogenesis and development of many types of human malignancies (13-15). The role of cell cycle regulators has been described recently in hepatoblastoma (6-8). However, the genetic analysis of the cyclin-dependent kinase inhibitors and cyclin Ds revealed that the $p 16$ and $p 15$ genes were transcriptionally silenced in hepatoblastomas as well as in nontumorous liver tissue (6). Thus, the role of p16 in the development of hepatoblastomas has been underestimated. Several mechanisms of the p16 inactivation, such as point mutation, homozygous deletion, loss of heterozygosity, and hypermethylation, have been reported in different types of human malignancies (19-21). Iolascon et al. (6) demonstrated the transcriptional silencing of $p 16$
A
12 3
$4 \quad 5 \quad 6$

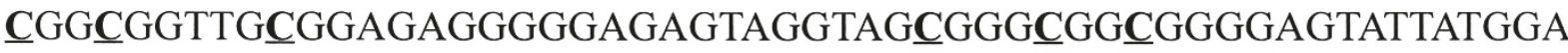 1
$\begin{array}{llll}7 & 8 & 9 & 10\end{array}$

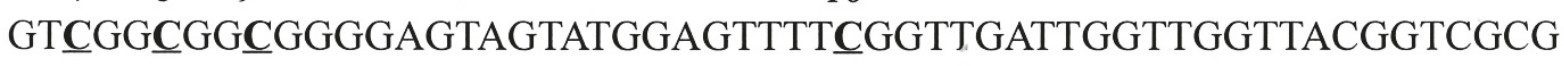

\section{GTTCGGGGTCAA}

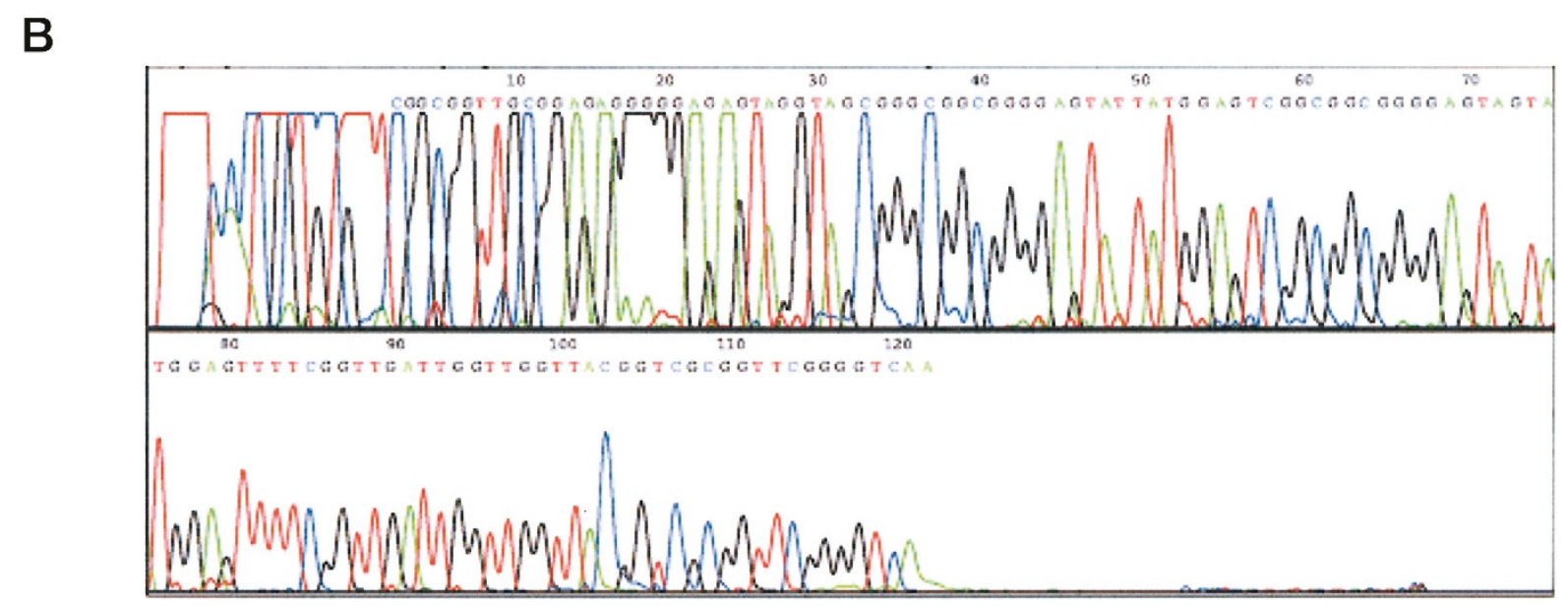

FIGURE 2. Methylation status at CpG sites of the $p 16$ gene in Case 10 . A, the nucleotide sequnces between +167 and +317 of the $p 16$ gene. The individual CpG sites are numbered sequentially. Cytosines at the CpG sites are in bold. B, all CpG sites contained methylated cytosine. 

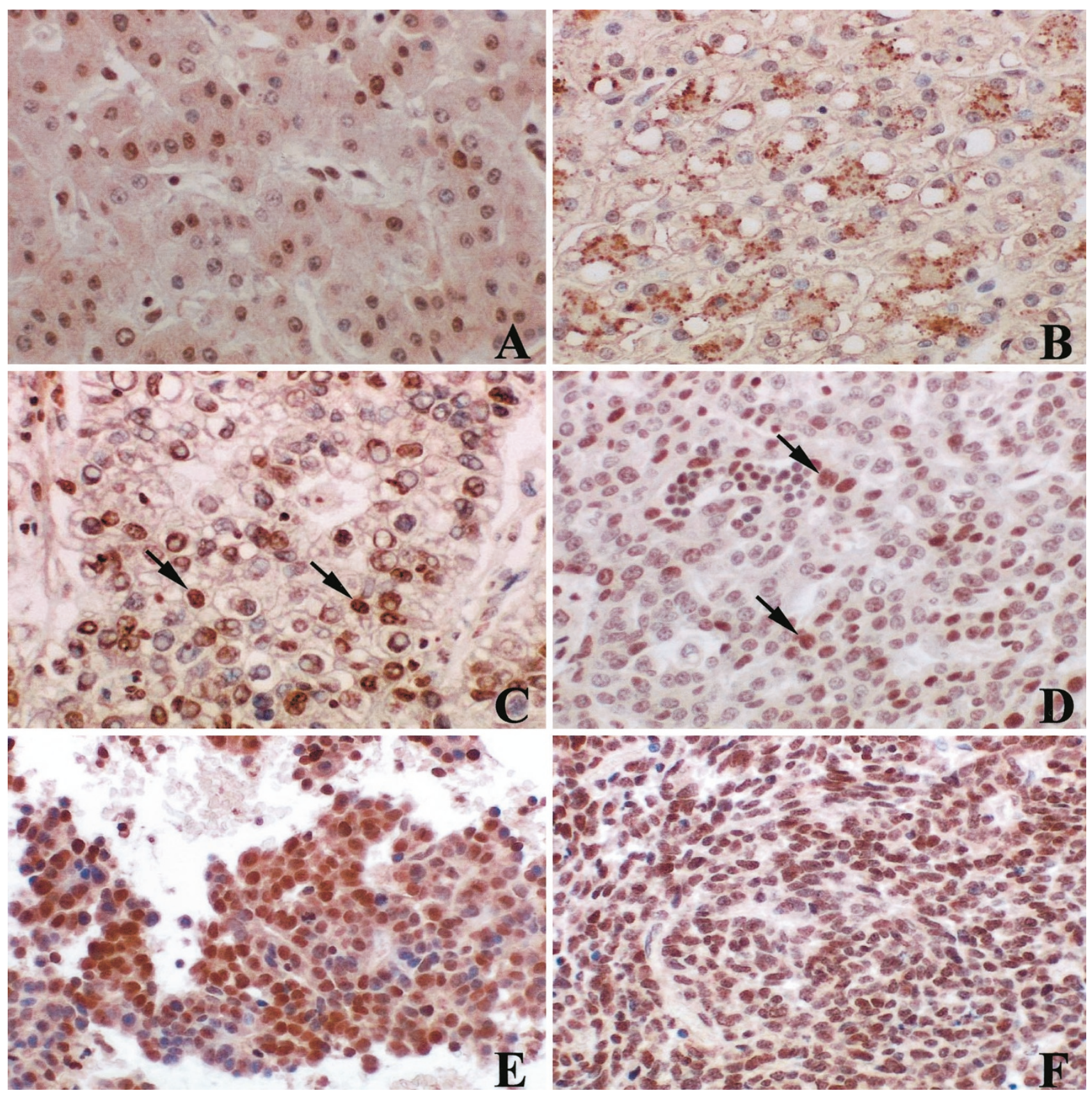

FIGURE 3. Immunohistochemical staining for p16. A, non-neoplastic liver displays moderate expression of p16 in the nucleus. B, a representative case of methylation-positive embryonal type hepatoblastoma; tumor cells are entirely negative for p16 (Case 8). Granular immunopositivity corresponds to the cytoplasmic pigment such as iron or lipofuscin pigments. C (Case 10) \& D (Case 12), two representative cases of methylationpositive hepatoblastoma exhibiting variably heterogeneous nuclear expression of p16 (arrows). E (Case 19) \& F (Case 14), two representative cases of methylation-negative hepatoblastoma: $>90 \%$ of tumor cells are strongly positive for p16 regardless of the histologic type.

in hepatoblastomas and examined genetic alterations including homozygous deletion, mutation, and loss of heterozygosity of $9 p 21$. However, they did not detect any genetic abnormalities of the $p 16$ gene in the cases they examined, and they did not investigate the methylation status of $p 16$. Thus, the high frequency of the $p 16$ hypermethylation in our cases suggests that the hypermethylation of $p 16$ is a major mechanism for the transcriptional repression of p16 in hepatoblastomas.
The aberrant methylation of $p 16$ indicates that the expression of p16 can be various in hepatoblastomas, because hypermethylation of the $p 16$ gene can repress the transcription of the gene, thereby affecting the protein expression. There were four subgroups of hepatoblastomas according to the methylation status of $p 16$ and the p16 expression. Among 12 cases of unmethylated hepatoblastoma, 9 cases $(66.6 \%)$ were positive for p16, whereas 8 of $12(75.0 \%)$ methylation-positive hepatoblastomas 
were not immunoreactive for p16. These observations indicate that the hypermethylation of $p 16$ plays an important role in the loss of p16 in hepatoblastoma as it does in the adult liver cancer, hepatocellular carcinoma.

In the present study, 4 cases of methylationpositive hepatoblastoma expressed p16 heterogeneously. This finding may be explained by a high sensitivity of the MSP method, or partial or hemimethylation of the $p 16$ gene. First, MSP is very sensitive and can detect methylated DNA at a level of $0.1 \%$ (16). If tumor cells contained both methylated and unmethylated DNA, and the proportion of methylated DNA was as low as $0.1 \%$ of the total DNA, the sample would be classified as having a methylation-positive pattern, but it would show positive immunoreactivity in $99.9 \%$ of unmethylated tumor cells. Thus the methylation status detected by the MSP method may need to correlate with an immunohistochemical analysis to validate the biological function of hypermethylation. Second, it has been reported that the reduction of p16 expression is associated with limited CpG methylation (20). This indicates that incomplete methylation may result in partial loss of p16 expression. In the analysis of methylation density in the three cases of hepatoblastoma that were positive for methylation and p16 expression in the present study, we found extensive methylation in all sequenced clones. These results suggest that partial methylation of the CpG island sites that were examined in this study did not contribute to the immunoreactivity in our cases. However, incomplete methylation at other $\mathrm{CpG}$ islands cannot be excluded. PCR results showed that both unmethylated and methylated DNA were present in all 4 cases. The unmethylated DNA in PCR analysis may be from either nontumor cells or an unmethylated population of tumor cells. The latter may account for the p16 expressing tumor cells of the present cases. Third, hemimethylation has been reported in cell lines such as the colon cancer cell line, HCT116 (22). The analysis of hemimethylation of tumor cells, however, is hampered by unmethylated DNA from nontumor cells in primary tumors. In addition, most methylation-positive cases with negative immunoreactivity also had unmethylated DNA, suggesting that the amplified unmethylated DNA could come mainly from non-tumor tissues. Therefore, the p16 immunopositivity in those cases is unlikely to be attributable to p16 hemimethylation.

The three cases that were negative for both methylation and immunoreactivity suggested that molecular mechanisms, such as homozygous deletion or genetic mutation, might be responsible for the lack of p16. Neither of these events, however, was detected in the study by Iolascon et al. (6). Further analysis is necessary to elucidate racial difference of the frequency of such genetic alterations in hepatoblastomas.

In conclusion, our data indicate that hypermethylation of the $p 16$ gene promoter is a major mechanism of the transcriptional inactivation of $p 16$ and accounts for the lack or decrease of p16 expression in hepatoblastomas. Thus, we suggest that the aberrant methylation status of $p 16$ may play an important role in the tumorigenesis of a subpopulation of hepatoblastomas.

Acknowledgments: The authors are grateful to Ms. Hyun Jung Kim and to Ji Young Jang for their technical assistance.

\section{REFERENCES}

1. Ding S-F, Michail NE, Habib NA. Genetic changes in hepatoblastoma. J Hepatol 1994;20:672-5.

2. Perilongo G, Shafford EA. Liver tumors. Eur J Cancer 1999; 35:953-8.

3. Albrecht S, von Schweinitz D, Waha A, et al. Loss of maternal alleles on chromosome arm 11p in hepatoblastoma. Cancer Res 1994;54:5041-4.

4. Oda H, Imai Y, Nakatsuru Y, Hata J, et al. Somatic mutation of the APC gene in sporadic hepatoblastoma. Cancer Res 1996;56:3320-3.

5. Oda H, Nakatsuru Y, Imai Y, et al. A mutational hot spot in the p53 gene is associated with hepatoblastoma. Int J Cancer 1995;60:786-90.

6. Iolascon A, Giordani L, Moretti A, et al. Analysis of CDKN2A, CDKN2B, CDKN2C, and cyclin Ds gene status in hepatoblastoma. Hepatology 1998;27:989-95.

7. Kim H, Ham EK, Kim YI, et al. Overexpression of cyclin D1 and cdk4 in tumorigenesis of sporadic hepatoblastomas. Cancer Lett 1998;131:177-83.

8. Gray SG, Hartmann W, Eriksson T. Expression of genes involved with cell cycle control cell growth and chromatin modification are altered in hepatoblastomas. Int J Mol Med 2000;6:161-9.

9. Sherr CJ. Cancer cell cycles. Science 1996;274:1672-7.

10. Serrano M. The tumor suppressor protein p16 ${ }^{\mathrm{INK} 4 \mathrm{a}}$. Exp Cell Res 1997;237:7-13.

11. Liggett WH, Sidransky D. Role of the p16 tumor suppressor gene in cancer. J Clin Oncol 1998;16:1197-206.

12. Sugimura T, Ushijima T. Genetic and epigenetic alterations in carcinogenesis. Mutat Res 2000;462:235-46.

13. Matsuda Y, Ichida T, Matsuzawa J, et al. p16INK4 is inactivated by extensive CpG methylation in human hepatocellular carcinoma. Gastroenterology 1999;116:394-400.

14. Liew CT, Li HM, Lo KW, et al. High frequency of p16 $6^{\text {INK4A }}$ gene alterations in hepatocellular carcinoma. Oncogene 1999;18:789-95.

15. Baek MJ, Piao Z, Kim N-G, et al. p16 is a major inactivation target in hepatocellular carcinoma. Cancer 2000;89:60-8.

16. Herman JG, Graff JR, Myohanen S, et al. Methylationspecific PCR: a novel PCR assay for methylation status of CpG islands. Proc Natl Acad Sci U S A 1996;93:9821-6.

17. Stocker JT, Husain AN, Dehner LP, Chandra RS. The liver, gallbladder, and biliary tract. In: Stocker JT, Dehner LP, editors. Pediatric pathology. 2nd ed. Vol 2. Philadelphia, PA: Lippincott Williams \& Wilkins, 2001:767.

18. Greenberg M, Filler R. Hepatic tumors. In: Pizzo PA, Poplack DG, editors. Principles and practice of pediatric oncology. 2nd ed. Philadelphia, PA: Lippincott; 1993. p. 703-10. 
19. Hui A-M, Sakamoto M, Kanai $\mathrm{Y}$, et al. Inactivation of p16 $6^{I N K 4}$ in hepatocellular carcinoma. Hepatology 1996;24: 575-9.

20. Matsuda Y, Ichida T, Matsuzawa J, et al. p16INK4 is inactivated by extensive CpG methylation in human hepatocellular carcinoma. Gastroenterology 1999;116:394-400.
21. Shim Y-H, Kang GH, Ro JY. Correlation of $p 16$ hypermethylation with p16 protein loss in sporadic gastric carcinomas. Lab Invest 2000;80:689-95.

22. Myohanen SK, Baylin SB, Herman JG. Hypermethylation can selectively silence individual p16INK4A alleles in neoplasia. Cancer Res 1998;58:591-3.

\section{Book Review}

\section{Aufderheide AC: The Scientific Study of Mum- mies, 626 pp, Cambridge, Cambridge Uni- versity Press, 2002 (\$150.00).}

Arthur C. Aufderheide, Professor of Pathology at The University of Minnesota (Duluth) and coauthor of The Cambridge Encyclopedia of Human Paleopathology, has given us, in this clearly written and very well-researched book, a fascinating, multifaceted study of mummified bodies throughout the ages.

After some introductory material concerning a historical survey of mummy studies, the intended purposes of deliberate (anthropogenic) mummification are discussed, as well as mechanisms of mummification. We then are introduced to a worldwide study of the geographical distribution of mummies, with correlation of the environmental, geophysical, and climatological factors involved in the mummification process, followed by the numerous cultural aspects of this subject. One reads about the discoveries of mummified bodies, which is written in such a clear and enthusiastic style that the reader feels that they themselves are a part of the archeological team.

It is the section on Paleopathology that a majority of Modern Pathology readers will most likely find of greatest interest. Here we have very concise but comprehensive coverage of various pathologic conditions that have been discovered in mummified bodies, including congenital, degenerative, inflammatory, and neoplastic processes. Numerous gross (black and white) pho- tographs accompany the textual material, and some histopathologic photomicrographs are included in various other chapters.

The last two sections cover "The Museology of Mummies," in which the various preservation methods are discussed. The text ends with a section titled "The Use and Abuse of Mummies." In this chapter we read of numerous anecdotal tales concerning unusual ways in which mummies have been treated throughout history, such as using mummified tissue as a medicine, as ornamental jewelry, as a curse, and as subject matter for both film and literature.

This text is well-referenced, and as is to be expected from a work of this nature, references are gathered from numerous fields of study, including archaeologic, anthropologic, historical, biochemical, bacteriologic, forensic, medical, and paleopathologic resources.

This is an enjoyable read. Professor Aufderheide's love of this subject comes through in each chapter. Even the lay reader, without any significant background in science, will gain from this book because of the author's lucid style, and I would recommend The Scientific Study of Mummies to anyone with even a fleeting interest in this subject.
Larry I. Giltman
VAMC-Atlanta
Emory University School of Medicine
Atlanta, Georgia 